\title{
Reversible intestinal mucosal abnormality in acrodermatitis enteropathica
}

\author{
ROBERT KELLY, GEOFFREY P. DAVIDSON, R. RUGELY W. TOWNLEY, AND \\ PETER E. CAMPBELL \\ From the Departments of Dermatology, Gastroenterology, and Pathology, Royal Children's Hospital \\ Melbourne, Australia
}

\begin{abstract}
Kelly, R., Davidson, G. P., Townley, R. R. W., and Campbell, P. E. (1976). Archives of Disease in Childhood, 51, 219. Reversible intestinal mucosal abnormality in acrodermatitis enteropathica. In 3 cases of acrodermatitis enteropathica duodenal biopsy performed at the outset of treatment showed a similar abnormality of the intestinal mucosa. Further biopsies taken during treatment showed progressive improvement of the intestinal mucosa with subsequent complete restoration of the normal cellular and villous pattern. The initial treatment was with expressed human breast milk and oral di-iodohydroxyquinoline. The latter was continued alone and later replaced by zinc sulphate. Changes in the intestinal epithelial cells and inflammatory cell infiltration of the lamina propria still detectable on di-iodohydroxyquinoline therapy reverted to normal with oral zinc.
\end{abstract}

Acrodermatitis enteropathica (Margileth, 1963) is a rare hereditary disorder of infancy characterized by distinctive cutaneous lesions primarily localized to the periorificial areas and extremities, alopecia (usually total), gastrointestinal symptoms, dystrophy of nails, and growth failure.

Neldner et al. (1974), in a recent survey, stated that light microscope examinations of the gastrointestinal tract in acrodermatitis enteropathica had been essentially normal, though they referred to a few reports of necropsied patients who had shown focal areas of mucosal degeneration at various levels in the jejunum, ileum, and colon.

Ament and Broviac (1973) reported one case in which a mucosal lesion in the small and large intestine did not revert to normal on therapy which included di-iodohydroxyquinoline (DIH). Moynahan (1962) reported duodenal biopsy with normal histology in an 18-month-old female with acrodermatitis enteropathica treated with DIH, though there was no mention of whether biopsy was taken before or after DIH. Fry, McMinn, and Schuster (1966) referred to 2 cases of acrodermatitis enteropathica in whom biopsy was taken before treatment was started, but did not describe any structural abnormality of the intestinal mucosa. In contrast, all 3 cases described in this report showed similar

Received 24 June 1975. intestinal mucosal abnormalities on duodenal biopsy at the outset of treatment and all reverted to normal with therapy.

\section{Case reports}

Case 1. A male aged 9 months presented with a rash of 6 months' duration which had appeared in the napkin area at 3 months and 2 weeks later around the mouth followed by ulceration in the mouth. It then spread around the eyes and nares and he developed blisters followed by areas of redness and scaling on the knees, hands, and feet. There was no diarrhoea. At birth black hair covered the scalp, but this was completely lost at 3 months of age. He was breast fed until $7 \frac{1}{2}$ months, and had received cereal with cow's milk and other solids from the age of 2 months. A younger brother is normal.

A diagnosis of acrodermatitis enteropathica had been made before admission to hospital and DIH had been administered in dosage of $1300 \mathrm{mg}$ daily for 9 weeks without significant improvement. After admission the dosage was doubled and expressed breast milk feed begun. The rash cleared and the dosage of DIH was progressively reduced with short temporary increases during mild recrudescences of rash which occurred with intercurrent infection. Expressed breast milk feeds were stopped after 2 months. This regimen was maintained for 5 years after which DIH was discontinued and zinc sulphate solution (50 mg three times daily) begun. Duodenal biopsy was performed 5 days after starting treatment with expressed breast milk and DIH and 
again after 4 weeks and 6 weeks of DIH therapy and before oral zinc. A further biopsy was obtained after 6 months' zinc therapy.

The rash cleared with DIH but after a cold he usually developed mild recurrences of rash which subsided with temporary increase in DIH dosage. On zinc sulphate, however, his skin has remained completely clear of rash at all times. Hair growth has remained normal. At the age of 6 years his height was $110 \mathrm{~cm}$ and weight $19 \cdot 25 \mathrm{~kg}$.

Case 2. A female aged 4 months presented with rash of 10 weeks' duration. One elder sister is normal. Ulcerated areas first appeared in the mouth at the age of 2 weeks, followed at 6 weeks by rash around the mouth and nares, on the cheeks, the back of the head, and the outer aspects of the ears. By 3 months the vulva, buttocks, inner thighs, knees, hands, and feet were affected and she developed diarrhoea with five or six liquid motions daily. Short sparse hair was present on the scalp and eyebrows and eyelashes were almost completely absent. She was fed on an artificial milk formula until the age of 4 months. A diagnosis of acrodermatitis enteropathica was made and treatment with expressed breast milk and DIH was begun.

DIH dosage was increased from $900 \mathrm{mg}$ to $1800 \mathrm{mg}$ daily with progressive improvement of the rash and cessation of diarrhoea. Expressed breast milk was stopped and DIH continued alone, the dosage ultimately being reduced to $900 \mathrm{mg}$ daily increasing up to $1800 \mathrm{mg}$ daily during minor recrudescences of rash and lethargy which occurred every 4 to 6 weeks. This was continued for 4 years when DIH was stopped and zinc sulphate solution ( $50 \mathrm{mg}$ three times daily) begun. Duodenal biopsies were carried out before any treatment was given and again after 3 weeks and before oral zinc. A further duodenal biopsy was obtained after 6 months' zinc therapy. On DIH there was regrowth of scalp hair, eyebrows, and eyelashes. There have been no relapses on zinc sulphate treatment. At the age of 5 years she weighed $18 \cdot 25 \mathrm{~kg}$ and height was $100 \mathrm{~cm}$.

Case 3. A male aged 5 months presented with a red, crusted rash of one-month duration appearing at first on the buttocks, groins, thighs, scrotum, and penis, with small patches elsewhere. It then appeared around the mouth and on the cheeks some days later. Scalp hair, eyebrows, and eyelashes were normal and there was no diarrhoea. He had been breast fed until the age of 3 months and was then changed to cow's milk. 3 elder brothers are normal. A diagnosis of acrodermatitis enteropathica was made and treatment begun with expressed breast milk alone. 10 days later DIH was added in dosage of $900 \mathrm{mg}$ daily increasing to $1800 \mathrm{mg}$ daily and then reducing to $900 \mathrm{mg}$ daily after the rash cleared. DIH was discontinued after 20 months and zinc sulphate solution (50 $\mathrm{mg}$ twice daily) begun. Duodenal biopsies were performed before DIH therapy, and again before oral zinc. A third biopsy was obtained after 6 months' zinc therapy. At $2 \frac{1}{2}$ years of age his weight was $16.55 \mathrm{~kg}$ and height $93 \mathrm{~cm}$.

Investigations. Haemoglobin estimations, skin and stool cultures, and serum immunoglobulins were investigated at initial presentation (see Table). Serum zinc levels were measured before, and several months after, starting oral zinc using the Varian Techtron AA3 spectrophotometer with an AA5 readout (Olson and Hamlin, 1968). Periodic eye examinations for optic neuritis were carried out in all patients when on DIH.

Duodenal biopsy. The biopsy procedure is described in detail elsewhere (Townley and Barnes, 1973). Specimens were taken from the fourth part of the duodenum.

\section{Results}

The initial biopsies taken before treatment or at the start of treatment showed loss of villous architecture with flattening of villi, which in some areas was as severe as that seen in coeliac disease. There was increased cellularity in the lamina propria due to infiltration with inflammatory cells. The intestinal epithelial cells were cuboidal in shape and the nuclei were enlarged, more rounded, and less elongated with an open chromatin distribution in contrast to the normal compact chromatin arrangement. This same pattern of change was seen in all 3 patients (Figs. $1 \mathrm{a}$ and $2 \mathrm{a}$ ).

TABLE

Investigations in 3 cases of acrodermatitis enteropathica

\begin{tabular}{|c|c|c|c|c|c|c|c|c|c|}
\hline \multirow{2}{*}{ Case no. } & \multirow{2}{*}{$\begin{array}{l}\text { Haemoglobin } \\
\text { (g/dl) }\end{array}$} & \multirow{2}{*}{$\begin{array}{l}\text { Skin } \\
\text { swab } \\
\text { culture }\end{array}$} & \multirow{2}{*}{$\begin{array}{l}\text { Stool } \\
\text { culture }\end{array}$} & \multirow{2}{*}{$\begin{array}{l}\text { Stool and } \\
\text { skin } \\
\text { culture } \\
\text { for } \\
\text { Candida } \\
\text { albicans }\end{array}$} & \multirow{2}{*}{$\begin{array}{l}\text { Serum } \\
\text { immuno- } \\
\text { globulins }\end{array}$} & \multicolumn{2}{|c|}{ Duodenal histology } & \multicolumn{2}{|c|}{$\begin{array}{c}\text { Serum zinc } \\
\text { (normal range } 75-140 \\
\mu \mathrm{g} / 100 \mathrm{ml} \text { ) }\end{array}$} \\
\hline & & & & & & $\begin{array}{l}\text { Before } \\
\text { zinc } \\
\text { therapy }\end{array}$ & $\begin{array}{l}\text { After zinc } \\
\text { therapy }\end{array}$ & $\begin{array}{c}\text { On di- } \\
\text { iodohydroxy- } \\
\text { quinoline }\end{array}$ & $\begin{array}{l}\text { On zinc } \\
\text { sulphate }\end{array}$ \\
\hline $\begin{array}{l}1 \\
2 \\
3\end{array}$ & $\begin{array}{l}11 \cdot 8 \\
12 \cdot 8 \\
13 \cdot 5\end{array}$ & $\begin{array}{l}\text { Staph. aureus } \\
\text { Staph. aureus } \\
\text { Staph. aureus }\end{array}$ & $\begin{array}{l}\text { NPI } \\
\text { NPI } \\
\text { NPI }\end{array}$ & $\begin{array}{l}\text { Negative } \\
\text { Negative } \\
\text { Negative }\end{array}$ & $\begin{array}{l}\text { Normal } \\
\text { Normal } \\
\text { Normal }\end{array}$ & $\begin{array}{l}\text { Abnormal } \\
\text { Abnormal } \\
\text { Abnormal }\end{array}$ & $\begin{array}{l}\text { Normal } \\
\text { Normal } \\
\text { Normal }\end{array}$ & $\begin{array}{l}28 \\
54 \\
65\end{array}$ & $\begin{array}{l}111 \\
110 \\
110\end{array}$ \\
\hline
\end{tabular}

NPI, no pathogen isolated. 
The biopsies taken after treatment with expressed breast milk and DIH showed partial re-establishment of villous architecture and reduction of the cellular infiltration of the lamina propria (Figs. 1b and $2 b$ ). The nuclei of the epithelial cells still showed the open distribution of the chromatin and were still more rounded than the normal elongated nucleus. Also the intestinal epithelial cell nuclei were located more centrally in the cell as compared with the normal basal location. After zinc sulphate therapy there was complete restoration of normal mucosa (Figs. 1c and 2c).

\section{Discussion}

This study clearly shows that in acrodermatitis enteropathica there is a small intestinal mucosal abnormality which is only partially corrected with
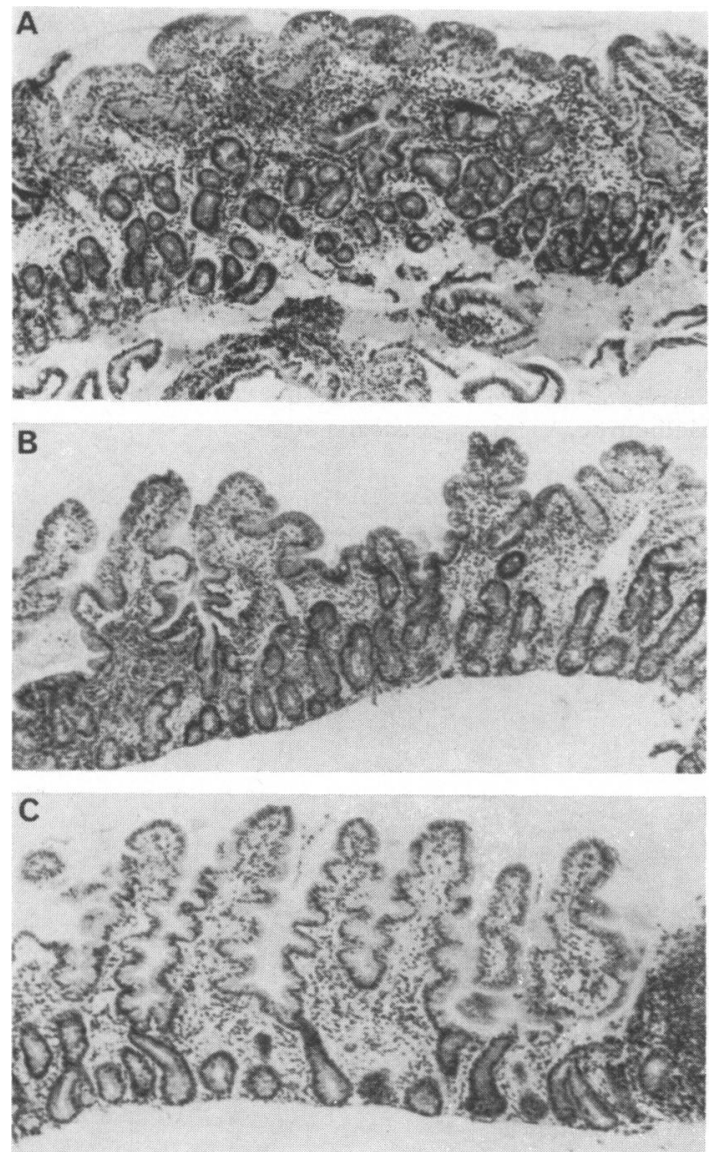

Fig. 1.-Case 1. Duodenal biopsy sections. (A) Bufore treatment. (B) After treatment with di-iodohydroxyquinoline. (C) After treatment with oral zinc. $(\times 30)$.
DIH but which is completely restored to normal after oral zinc therapy. Since the abnormalities in the intestinal mucosa seem to improve at the same time as the skin changes during treatment with expressed breast milk and DIH, it may be that the intestinal mucosal changes are dependent on the same agency as the skin changes.

Remission of the clinical manifestations of the disease occurred in all 3 patients on DIH treatment
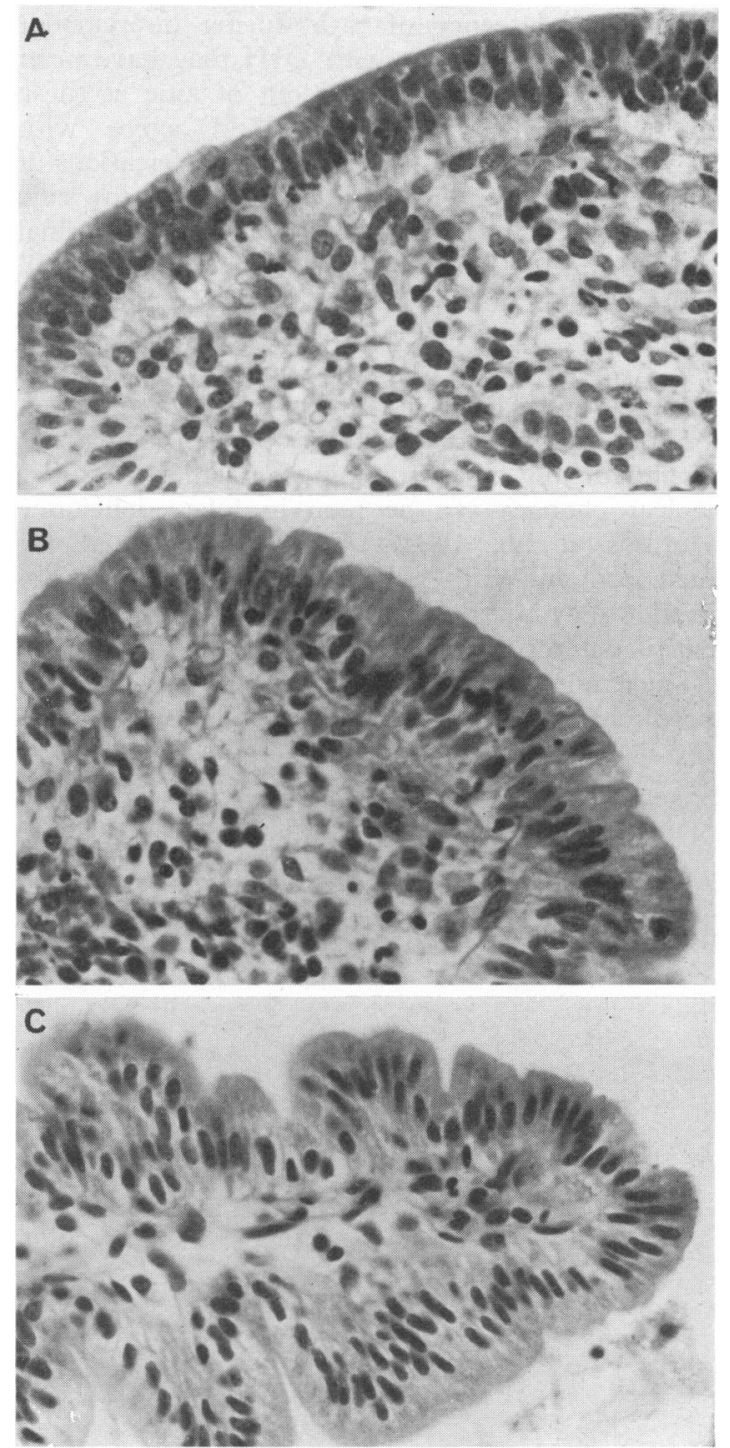

Fig. 2.-Case 1. Duodenal biopsy sections. ( $A$ ) Before treatment. (B) After treatment with di-iodohydroxyquinoline. (C) After treatment with oral zinc. $(\times 365$. 
but with some recrudescence of rash with intercurrent infection. All had low serum zinc levels which rose to normal after oral zinc sulphate (see Table). Thus oral zinc therapy maintains complete clinical remission, normal serum zinc levels, and normal histology of the small intestinal mucosa. However, the intestinal mucosa was still abnormal on DIH therapy. This may have been due specifically to zinc deficiency which disappeared with oral zinc and restored normal levels. The minor recrudescence of rash during intercurrent infections on treatment with DIH may have been due to an increased requirement of zinc at these times. These observations would agree with Moynahan's postulate that all the manifestations of acrodermatitis enteropathica are due to zinc deficiency (Moynahan, 1974). The intestinal mucosa and the hair matrix have a high rate of cell multiplication and it would be likely that their morphology and function could be affected by zinc deficiency. Thus the appearance of the intestinal epithelial cells and the nuclei may reflect abnormal synthesis of nucleoprotein which is dependent on zinc-containing enzymes. Similar nuclear changes can be seen in folate deficiency (Hermos et al., 1972). Folate is essential for nucleoprotein synthesis and by analogy zinc deficiency may be the responsible factor in acrodermatitis enteropathica.

Since most previous reports of the small intestinal morphology in this disease did not show abnor- mality, or where found failed to revert with treatment (Ament and Broviac, 1973), further duodenal biopsy studies are indicated to show the true frequency of the intestinal mucosal abnormality in acrodermatitis enteropathica.

We thank the Department of Photography for their help; Mrs. R. Kay for the histology; and Mrs. Carol Bumak for the serum zinc estimations.

\section{REFERENCES}

Ament, M. E., and Broviac, J. (1973). Acrodermatitis enteropathica: demonstration of small and large intestinal mucosal lesions: failure of hyperalimentation, Intralipid and Diodoquin to reverse the intestinal lesions and generalized malabsorption syndrome. Gastroenterology, 64, 692 .

Fry, L., McMinn, R. M. M., and Schuster, S. (1966). The small intestine in skin diseases. Archives of Dermatology, 93, 647.

Hermos, J. A., Adams, W. H., Lui, Y. K., Sullivan, L. W., and Trier, J. S. (1972). Mucosa of the small intestine in folatedeficient alcoholics. Annals of Internal Medicine, 76, 957.

Margileth, A. M. (1963). Acrodermatitis enteropathica. Case report and review of literature. American fournal of Diseases of Children, 105, 285.

Moynahan, E. J. (1962). Acrodermatitis enteropathica. Proceedings of the Royal Society of Medicine, 55, 240.

Moynahan, E. J. (1974). Acrodermatitis enteropathica: a lethal inherited human zinc-deficiency disorder. Lancet, 2, 399.

Neldner, K. H., Hagler, L., Wise, W. R., Stifel, F. B., Lufkin, E. G. and Herman, R. H. (1974). Acrodermatitis enteropathica. Archives of Dermatology, 110, 711 .

Olson, A. D., and Hamlin, W. B., (1968). Serum copper and zinc: a new method of using atomic absorption spectrophotometry. Atomic Absorption Newsletter, 7, no. 4, 69.

Townley, R. R. W., and Barnes, G. L. (1973). Intestinal biopsy in childhood. Archives of Disease in Childhood, 48, 480.

Correspondence to Dr. R. Kelly, 20 Collins Street, Melbourne, Victoria, Australia 3000. 